\title{
Retina kan damarlarını çıkarmak için eşikleme temelli morfolojik bir yöntem
}

\section{A threshold-based morphological method for extraction blood vessels from retina}

\author{
Buket Toptaş, ${ }^{1} *$ (D), Davut Hanbay ${ }^{2}$ (iD) \\ ${ }^{I^{*}}$ Bandırma Onyedi Eylül Üniversitesi, Bilgisayar Mühendisliği Bölümü, Bandırma, Balıkesir, Türkiye \\ ${ }^{2}$ İnönü Üniversitesi, Bilgisayar Mühendisliği Bölümü, 44280,Malatya, Türkiye
}

\begin{abstract}
Özet
Son yıllarda, diyabete bağlı retina hastalığı körlüğün önde gelen nedenlerinden biri haline gelmiştir. $\mathrm{Bu}$ hastalığın önüne geçebilmek için retina ă̆ yapısının doğru bölütlenmesi gerekir. Retina ağ yapısının doğru ve hızlı bölütlenmesi için bilgisayar destekli tanı sistemlerine ihtiyaç duyulur. $\mathrm{Bu}$ makalede, renkli retina fundus görüntüsü üzerinde retina damarlarını otomatik olarak bölütleyen bir yöntem önerilmiştir. Retina damar a ğ yapısını bölütlemek için morfolojik işlemlere dayalı bir yöntem retina görüntüleri üzerine uygulanmıştır. Morfolojik işlemlerin uygulandığı fundus görüntüsüne üç farklı eşikleme yöntemi uygulanmıştır. Bu eşikleme yöntemleri; Çoklu Eşikleme, Maksimum Entropi Tabanlı Eşikleme ve Bulanık Kümeleme Tabanlı Eşikleme yöntemleridir. Eşikleme sonucunda bölütlenmiş damar görüntüleri elde edilmiştir. $\mathrm{Bu}$ makalede amaç farklı eşikleme algoritmalarının aynı görüntüler üzerindeki performans karşılaştırmasını sağlamaktır. Uygulanan yöntem, herkese açık olarak sunulan retina görüntü veri seti üzerinde doğrulanmıştır. Deneysel sonuçlar, önerilen yöntemin doğru bir şekilde tespit edebildiğini göstermektedir. Eşikleme algoritmalarının 40 görüntüden oluşan veri seti üzerindeki doğruluk oranı Bulanık Mantık Tabanlı Eşikleme için 0.952, Maksimum Entopi Tabanlı Eşikleme için 0.950 ve Çoklu Eşikleme için 0.925 olarak hesaplanmıştır.
\end{abstract}

Anahtar kelimeler: Retina, Fundus, Eşikleme yöntemleri, Morfolojik işlemler

\section{Giriş}

Diyabete bağlı retina bozuklukları kişilerde körlüğe sebep olan ve Diyabetik Retinopati (DR) olarak adlandırılan en önemli hastalıklardan biridir. Bu hastalığın erken teşhis edilmesi, kişilerde görme yetisinin kaybolmaması açısından önemlidir. DR hastalığının erken ve doğru teşhis edilmesi için retina damarlarının doğru bir şekilde bölütlenmesi gerekir. Retina görüntülerinin tespit edilmesi için bilgisayar destekli sistemler geliştirilmiştir. $\mathrm{Bu}$ sistemler yenilikçi yöntemler kullanarak sürekli geliştirilmektedir.

Literatürde retina damar bölütleme işlemi ișin geleneksel yöntemler ve son zamanlarda popüler hale gelen derin öğrenme yöntemleri önerilmiştir. Derin öğrenme yöntemleri ile retina damar bölütleme sistemlerinin geliştirilmesi daha sağlam sonuçlar verir ancak donanım bağlılığı gerektirir. Ancak geleneksel yöntemler olarak adlandırılan
Abstract

In recent years, the diabetes-related retinal disease has become one of the leading causes of blindness. In order to prevent this disease, the retinal network structure needs to be segmented correctly. Computer-aided diagnostic systems are required for accurate and fast segmentation of the retinal network structure. In this paper, a method is proposed to segments retinal vessels automatically in the color retinal fundus image. A method based on morphological procedures to segmentation of vessels has been applied on retinal images. Three different thresholding methods were applied to the fundus image obtained as a result of morphological processes. These thresholding methods are; Multiple Thresholding, Maximum Entropy Based Thresholding and Fuzzy Cluster Based Thresholding methods. As a result of thresholding, segmented vessel images were obtained. The aim of this paper is to show the performance comparison of different thresholding algorithms on the same images. The method applied has been validated on the retinal image data set that is publicly available. The experimental results show that the proposed method can accurately detect. The accuracy ratio of the thresholding algorithms on the data set consisting of 40 images was calculated as 0.952 for Fuzzy Logic Based Threshold, 0.950 for Maximum Entopy Based Threshold and 0.925 for Multiple Threshold.

Keywords: Retina, Fundus, Threshold Methods, Morphological processes

denetimli/denetimsiz öğrenme yöntemleri [1-9], morfolojik yöntemler [10-12], uyum süzgeci [13] gibi yöntemler daha hızlı ve daha anlaşılabilir yöntemlerdir. Bu makalede geleneksel bir yöntem olan morfolojik tabanlı bir yöntem kullanılmış olup literatürde önerilen diğer yöntemler şöyledir:

Soares vd. [2] tarafından retina görüntülerinin piksel parlaklık değerleri üzerinde faklı ölçeklerde Gabor-Dalgacık dönüşümü uygulanmıştır. Elde edilen farklı ölçekteki GaborDalgacık dönüşüm çıktıları özellik olarak kullanılmıştır. Daha sonra tüm görüntüye Bayes Sinıflandırıcı uygulanarak fundus görüntüleri damar ya da damar olmayan bölgelere ayrılmıştır. Niemeijer vd. [5], piksel sınıflandırma yöntemini önermişlerdir. Önerdikleri bu sistemde Matematiksel Morfoloji, Bölge Büyütme, Eşleştirilmiş Filtre ve Doğrulama Tabanlı Yerel Eşik yaklaşımı karşılaştırılmıştır.

\footnotetext{
* Sorumlu yazar / Corresponding author, e-posta / e-mail: btoptas@bandirma.edu.tr (B. Toptas)

Geliş / Recieved: 21.03.2021 Kabul / Accepted: 13.09.2021 Yayımlanma / Published: 14.01.2022

doi: 10.28948/ngmuh.900696
} 
Diego Marín vd. [6] tarafından fundus görüntüsündeki her pikselden yedi boyutlu bir özellik vektörü çıkarılmıştır. Çıkarılan özellikler sinir ağı kullanılarak sınıflandırılmıştır. Sınıflandırma aşamasında öncelikle tespit edilen piksellerin boşlukları doldurulmuş, daha sonra hatalı tespit edilen damar pikselleri damar olmayan olarak yeniden sınıflandırılmıştır. M. Elena Martinez-Perez vd. [14] tarafindan hessian matrisinin özdeğer analizine dayanan bir çizgi geliştirme filtresi önerilmiştir. Daha sonra gradyan büyüklügü ve temel eğrilik kullanılarak özellik çıkarılmıştır. Bu iki özellik damar veya arka plan olarak sınıflandırılması için Bölge Büyütme yaklaşımında kullanılmıştır. Sven Holm vd. [15] tarafından damar bölütleme için iki paralel yöntem önerilmiştir. $\mathrm{Bu}$ yöntemlerden ilki sadece fundus görüntünün piksel yoğunluğunu kullanarak damar ve damar olmayan pikselleri bölütlere ayırmaktadır. İkinci yöntem ise tamamen damar yoğunluğunu kullanarak fundus görüntülerinde yerel gürültüyü azaltıp damar bölütlemeyi sağlayan birkaç adımdan oluşmaktadır. Chengzhang Zhu vd. [16] tarafından Aşırı Öğrenme Makinesine dayalı denetimli bir yöntem önerilmiştir. Bölütleme aşamasında, bölütleme görüntüsünden çıkarılan özellik vektörü eğitim aşamasında elde edilen sınıflandırıcının girişi olarak kullanılmıştır. Eğitim aşaması için, eğitim görüntüsünün her pikselinden bir özellik vektörü çıkarılmıştır. Sınıflandırıcının çıktısı, ikili retina damar bölütleme sonucu olmuştur. Jingliang Zhao vd. [17] tarafından öncelikli olarak fundus görüntüler üzerinde görüntü iyileştirilmesi yapılmıştır. İyileştirilmiş görüntüler üzerinde Süper Piksel (SLIC) yöntemi uygulanmış ve bölütleme gerçekleştirilmiştir. Ardından otomatik olarak seçilen düğüm noktalarından damar takibine başlanmış ve belirlenen durma kriterine ulaşıldığında takip işlemi sonlanmıştır.

Retinanın oksijensiz kalması sonucu retinada istenmeyen yeni damarlar oluşur. Bu damarlar hassas bir yapıda olup DR hastalığının habercisidir. $\mathrm{Bu}$ istenmeyen damarları tespit etmek için retina damar ağ yapısının bilinmesi gerekir. Bu makalede, retina damar ağ yapısını otomatik olarak bölütleyen morfolojik tabanlı bir yöntem önerilmiştir. $\mathrm{Bu}$ yöntem morfolojik işlemlere dayalı iki farklı yöntemden esinlenerek oluşturulmuştur. Bu yöntemde, ilk önce RGB renk uzayındaki görüntüler gri ölçekli görüntülere dönüştürülmüştür. Daha sonra, gri ölçekli görüntünün tersi üzerinde üst-şapka, alt-şapka ve morfolojik açma yöntemi uygulanmıştır. Morfolojik üst ve alt şapka yöntemin kullanılması ile retina damalarının belirginleştirilmesi sağlanmıştır. Belirginleştirilmiş retina görüntülerini bölütlemek için üç farklı eşikleme yöntemi kullanılmıştır. Kullanılan eşikleme yöntemleri Çoklu Eşikleme yöntemi, Maksimum Entropi Tabanlı Eşikleme yöntemi ve Bulanık Kümeleme Tabanlı Eşikleme yöntemidir. Önerilen yöntem literatürdeki diğer geleneksel yöntemlerle de kıyaslanabilir olması için halka açık olarak sunulan DRIVE veri seti üzerinde test edilmiştir. Bu makalede, literatürdeki mevcut çalışmalardan farklı olarak retina fundus görüntüleri üzerinde farklı eşik algoritmalarının kıyaslanması yapılmıştır.

Makalenin organizasyonu şöyledir. İkinci bölümde Materyal ve Metot anlatılmaktadır. Üçüncü bölümde
Kullanılan Yöntemden bahsedilir. Dördüncü bölümde Bulgular ve Tartışmadan bahsedilir. Son bölümde ise Sonuçlar bölümü bulunmaktadır.

\section{Materyal ve metot}

$\mathrm{Bu}$ bölüm, önerilen yöntemin arkasındaki ilgili teorik materyal ve metotların kısa bir incelemesini içerir. İlgili her çalışma sonraki alt bölümlerde detaylandırılmıştır.

\subsection{Morfolojik işlemler}

Morfolojik işlemlerin temel amacı, görüntünün temel özelliklerini korumak ve görüntüyü basitleştirmektir. Bu çalışmada, üst-şapka ve alt-şapka dönüşümleri kan damarlarına belirginlik kazandırmak için kullanılır. Üstşapka dönüşümü, bir giriş görüntüsüne morfolojik açma işlemi uygulandıktan sonra uygulama sonucunun orijinal giriş görüntüsünden çıkarılması işlemidir. $\mathrm{Bu}$ işlemin matematiksel ifadesi Denklem (1)'de verilmiştir. Alt-şapka dönüşümü, bir giriş görüntüsüne morfolojik bir kapama işlemi uygulandıktan sonra uygulama sonucunun orijinal giriş görüntüsünden çıkarılması işlemidir. $\mathrm{Bu}$ işlemin matematiksel ifadesi Denklem (2)'de verilmiştir.

$$
\begin{aligned}
& T_{\text {hat }}(g)=g-(g \circ S E) \\
& B_{\text {hat }}(g)=(g \bullet S E)-g
\end{aligned}
$$

Burada, ○ operatörü morfolojik açma işlemini, • operatörü ise morfolojik kapama işlemini temsil etmektedir. $S E$ parametresi ise, bir yapı elemanıdır. Bu çalışmada, açılma operatörü için $21 \times 21$ 'lik bir disk yapı elemanı, alt ve üstşapka dönüşümleri için ise uzunluğu 21 olan bir çizgi yap1 elemanı kullanılmıştır.

Denklem (1) 'e göre, açma operatörü görüntünün arka planına etki ettiğinden, üst-şapka dönüşümünün görüntünün arka planını çıkarması beklenir. $\mathrm{Bu}$ dönüşüm, yüksek geçirgen bir filtre gibi davranır ve görüntünün maskeden daha küçük olan parlak alanlarını çıkarır. Denklem (2) 'ye göre, alt-şapka dönüşümü görüntünün arka planını etkiler ve görüntünün arka plandaki maskeden daha küçük olan bazı karanlık alanları üzerinde etkili olur. Parlak alanları (açma operatörünün sonuçları) görüntüye eklemek ve karanlık alanları (kapama operatörünün sonuçları) görüntüden çıkarmak mümkündür. Sonuç olarak, aydınlık ve karanlık alanlar arasındaki kontrastta bir iyileşme olacaktır.

\subsection{Eşikleme yöntemleri}

Görüntü eşikleme sadeliği ve sağlamlığ nedeni ile en sık kullanılan görüntü bölütleme yöntemlerinden biridir. Eşikleme işlemi, gri ölçekli bir görünün yoğunluk seviyesine göre sınıflara ayrıldığı bir işlemdir. Bu sınıflandırma işlemi için tanımlanmış kurallara uygun bir eşik değeri seçmek gerekir. $\mathrm{Bu}$ çalışmada kullanılan eşikleme yöntemleri şöyledir;

\subsection{1 Çok seviyeli eşikleme}

Gri ölçekli görüntüyü birkaç farklı bölgeye ayırabilen bir işlemdir [18]. Bu işleme ait uyulması gereken kural Denklem (3)'de matematiksel olarak ifade edilmiştir. 


$$
\begin{aligned}
& C_{1} \leftarrow p \text { if } 0 \leq p<t h \\
& C_{2} \leftarrow p \text { if } \text { th } \leq p<L-1
\end{aligned}
$$

Burada, $p$ parametresi $L$ gri tonlama seviyeleri $\mathrm{L}=\{0,1$, $2, \ldots, \mathrm{L}-1\}$ ile temsil edilebilen gri tonlama görüntüsünün piksellerinden biridir. $C 1$ ve $C 2$ parametreleri, $p$ pikselinin atanacağ 1 sınıflardır, $t_{h}$ parametresi ise eşik değeridir.

\subsubsection{Maksimum entropi tabanll eşikleme}

Entopi yöntemlerine bağlı eşikleme işlemi araştırmacılar tarafindan tercih edilen bir yöntemdir [19]. Otsu'nun eşikleme algoritmasından farklı olarak sınıflar arasındaki varyansı maksimize etmek ya da sınıf içi varyansı minimize etmek yerine sınıflar arası entropi maksimize edilir. Bu yönteme göre, bir görüntüdeki yoğunluk değerlerinin olasılık dağılımına katkı veren ön ve arka plan görüntüsüne ait entropi değerleri ayrı ayrı hesaplanır ve toplamları maksimize edilir. Ardından, entropinin toplamını maksimize eden bir optimum eşik değeri hesaplanır [20]. Arka ve ön plan görüntüsüne ait entropi değeri Denklem (4) ve Denklem (5)'de verilmiştir. Denklem (6) arka ve ön plan görüntüsüne ait entropi değerlerinin maksimize edilmiş halidir.

$$
\begin{gathered}
H_{b}(t)=-\sum_{i=0}^{t} \frac{P_{i}}{P_{t}} \log _{e}\left(\frac{P_{i}}{P_{t}}\right) \\
H_{w}(t)=-\sum_{i=t+1}^{l-1} \frac{P_{i}}{1-P_{t}} \log _{e}\left(\frac{P_{i}}{1-P_{t}}\right) \\
t^{*}=\underset{t \in G}{\operatorname{ArgMax}}\left\{H_{b}(t)+H_{w}(t)\right\}
\end{gathered}
$$

Burada, $t$ eşik değerini temsil eder, $P_{t}$ parametresi $P_{t}=\sum_{i=0}^{t} P_{i}$ olarak hesaplanır. $P_{i}$ parametresi görüntüdeki $i$ gri düzeyinin olasılığgidır.

\subsubsection{Bulanık mantık tabanlı eşikleme}

Bulanık kümeleme bir yumuşak kümeleme tekniğidir. Bu kümeleme yöntemi, nesnelerin kümelere olan aitliğini ifade etmek için bir derece kavramı kullanır [21]. Her nesne için, toplam derece 1'dir. Denklem (7) her pikselin üyelik değerini hesaplamak için kullanılır.

$$
u_{i, j}=\frac{1}{\sum_{k=1}^{c}\left[\frac{\left\|x_{i}-c_{j}\right\|}{\left\|x_{i}-c_{k}\right\|}\right]^{\frac{2}{m-1}}}
$$

Burada, $u_{i j}$ parametresi üyelik fonksiyonunu, $x_{i}$ parametresi bireysel piksel değerini, $c_{j}$ ve $c_{k}$ parametreleri küme merkezini ve $m$ parametresi 1 'den fazla gerçek değeri temsil etmektedir.
Bölütleme görüntülerini ikili görüntülere dönüştürmek için kullanılacak eşik hesaplaması Denklem (8) ve Denklem (9) da verildiği gibidir.

$$
\begin{aligned}
& \text { Seviye } 0=\frac{\max (\mathrm{I}(\mathrm{c} 1==1))+\min (\mathrm{I}(\mathrm{c} 2==2))}{2} \\
& \text { Seviye } 1=\frac{\max (\mathrm{I}(\mathrm{c} 2==1))+\min (\mathrm{I}(\mathrm{c} 3==3))}{2}
\end{aligned}
$$

Burada, c parametresi sınıfı, I parametresi görüntüyü ve Seviye parametresi denklemden gelen eşik değeridir.

\section{Kullanılan yöntem}

Önerilen yöntemde, veri setinde bulunan fundus görüntülerine ait damarların bölütlenmesi sağlanmıştır. Öncelikle, veri setinde bulunan görüntüler RGB renk uzayından gri ölçekli görüntülere dönüştürülür. Gri ölçekli görüntülerin tersi üzerinde önerilen sistem uygulanır. Şekil 1'de veri setine ait bir görüntü ve bu görüntüye ait gri ölçekli görüntü ile gri ölçekli görüntünün tersi verilmiştir. Önerilen sistemin genel yapısı ise Şekil 2'de verildiği gibidir.
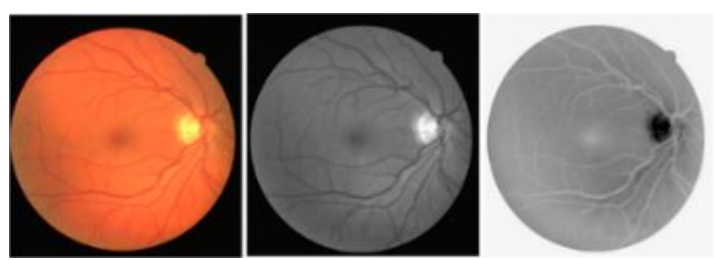

Şekil 1. Örnek veri seti görüntüsü, Sırasıyla, orijinal RGB görüntü, Gri-Ölçekli görüntü, Gri-Ölçekli görüntünün tersi

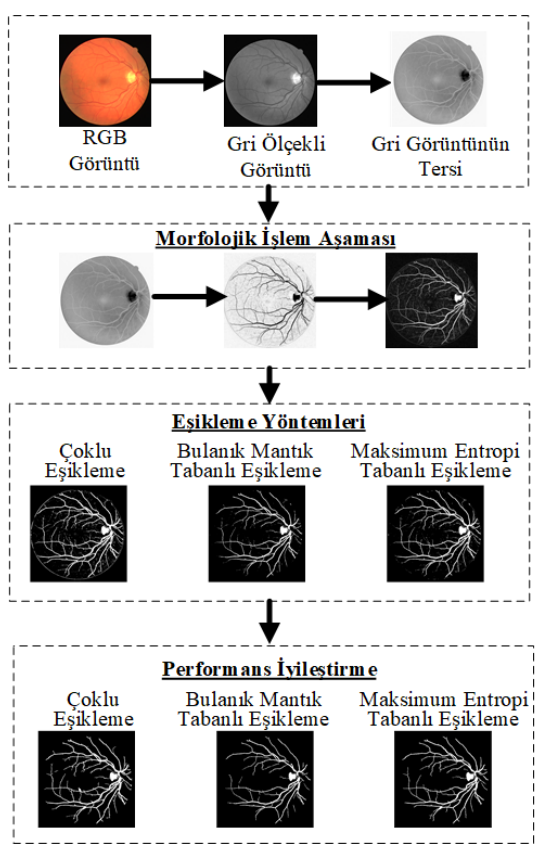

Şekil 2. Akış şeması

\subsection{Veri seti}

Önerilen yöntem diğer yöntemlerle kıyaslanabilir olması açısından halka açık olarak sunulan DRIVE veri seti üzerinde test edilmiştir. DRIVE veri setindeki görüntüler $45^{\circ}$ 
görüş alanında Canon 3CCD ile çekilmiştir. Görüntülerin her biri $565 \times 584$ piksel boyutunda 20 eğitim ve 20 test görüntüsünden oluşmaktadır. Veri setindeki damar pikselleri, deneyimli bir göz doktoru tarafindan eğitilmiş üç gözlemci tarafından manuel olarak bölümlere ayrılmıştır. Test seti iki farklı gözlemci tarafindan iki kez bölütlendirilmiş görüntülerden oluşur.

\subsection{Morfolojik işlemler}

Retina kan damarları, retina arka planına göre daha koyu görünürler. Ancak, bazı durumlarda kan damarlarının merkez çizgisi bölgesinde parlaklık görünür. Bu görünüm yansımalardan kaynaklanmaktadır. $\mathrm{Bu}$ durumu ortadan kaldırmak için ilk önce morfolojik açma işlemi uygulanır. Morfolojik açma işlemi için yarıçapı 21 olan bir disk oluşturulur. Oluşturulan bu disk gri ölçekli görüntünün tersine uygulanarak morfolojik açma işlemi yapılmış olur. Daha sonra uzunluğu 21 olan bir çizgisel yapı elemanı oluşturulur. Oluşturulan bu çizgisel yapı elemanı gri ölçekli görüntünün tersine uygulanarak üst-şapka ve alt-şapka dönüşümleri tamamlanmış olur. Şekil 3'de bu aşamaya kadar anlatılan işlemler görsel olarak ifade edilmiştir.
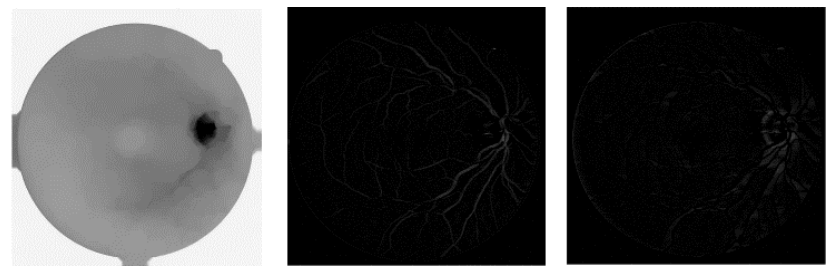

Şekil 3. Morfoljik işlemler. Sırası ile morfolojik açma, üst şapka ve alt şapka işlemleri

Belirli bir açıda yönlendirilmiş çizgisel bir yapılandırma elamanı fundus içerisinde tutulamadığında bir damarı veya damarın bir kısmını yok edebilir. Bu problem genelde yapılandırma elemanı dikey yönlere sahip olduğunda ve yapılandırma elemanı damar genişliğinden daha büyük olduğu durumlarda ortaya çıkmıştır. Oysa yapılandırma elemanının yönü ile damar paralel olduğunda bir yok olma olayı meydana gelmeyecektir. M. Fraz vd. [11], bu probleme çözüm olması için 21 piksel uzunluğunda bir çizgisel yapılandırma elemanı belirlemiştir. $\mathrm{Bu}$ yapısal elemanı $22.5^{\circ}$ 'lik açılarla döndermiş ve en büyük çapa sahip damarı çıkarmak için bir toplam üst şapka dönüşümü kullanmıştır. M. Fraz vd. [11] tarafindan önerilen toplam üst şapka dönüşümünden esinlenerek her biri 21 piksel uzunluğunda bir çizgiyi temsil eden ve her $22.5^{\circ}$ 'de döndürülen bir çizgi yapılandırma elemanı sadece üst şapkaya değil ayrıca alt şapka ve morfolojik açma işlemine uygulanmıştır. Denklem (10)'da toplam üst şapka işlemine dahil edilen toplam alt şapka ve toplam morfolojik açma işlemi matematiksel olarak ifade edilmiştir. Şekil 4'te bu aşamaya ait işlem sonuçları görsel olarak verilmişstir.

$$
\begin{aligned}
& I s_{t h}=\sum_{\theta \in A} I_{t h}^{\theta} \\
& I S_{b h}=\sum_{\theta \in A} I_{t h}^{\theta} \\
& I S_{o}=\sum_{\theta \in A} I_{o}^{\theta}
\end{aligned}
$$

Burada, $I s_{t h}, I s_{b h}$ ve $I s_{o}$ parametreleri sirasiyla $\theta$ derecelerde yapısal elemanın üst-şapka, alt-şapka ve morfolojik açma işlemlerinin toplamıdır. A parametresi, $\{x \mid 0 \leq x \leq 180$ ve $x \bmod (22.5)=0\}$ olarak tanımlanır.
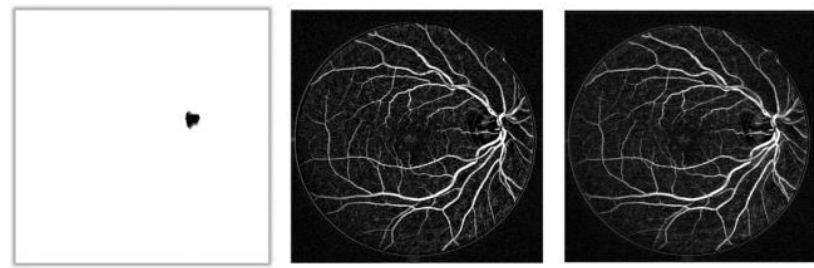

Şekil 4. Morfolojik işlem döngü sonucu. Sırasıyla morfolojik açma, üst-şapka ve alt-şapka sonuçları. (Bkz. Denklem (10))

Daha sonra, M. D. Saleh vd. [12] tarafindan önerilen matematiksel ifade kullanılmış ve Denklem (10)' da elde edilen sonuçlar bu matematiksel ifadeye göre nihai sonuca ulaşmıştır. M. D. Saleh vd. [12]' de verilen matematiksel ifadede morfolojik açma işleminin üzerine üst-şapka sonucu eklenerek elde edilen sonuç alt-şapka sonucundan çıkarılır. Önerilen yöntemde Denklem (10)' dan elde edilen toplam morfolojik açma, toplam üst şapka ve toplam alt şapka sonuçları Denklem (11)'de ifade edildiği gibi işleme alınmıştır. Uzunluğu 21 piksel olan ve $22.5^{\circ}$ lik açılarla dönerek her açı için oluşturulan toplam morfolojik açma işlemi toplam üst şapka dönüşümüne eklenmiş ve elde edilen sonuç toplam alt şapka dönüşümünden çıkarılmıştır. Bu aşamaya ait görsel sonuçlar Şekil 5'de sunulmuştur.

$$
I=\left(I s_{o}+I s_{t h}\right)-I s_{t b}
$$
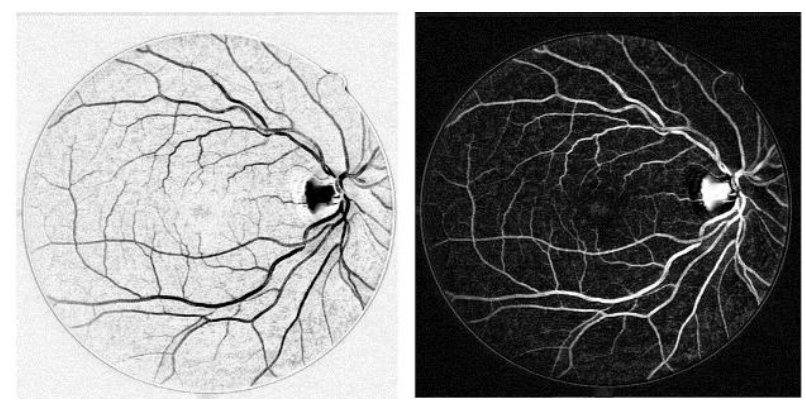

Şekil 5. Önerilen yöntem sonucu. İlk görüntü Denklem (11) sonucu, İkinci görüntü ilk görüntünün tersi alınmış halidir.

\section{Bulgular ve tartışma}

\subsection{Bölütleme sonuçlart}

Üç farklı eşikleme algoritması iyileştirilmiş fundus görüntüleri üzerinde uygulanarak damar piksellerinin bölütlenmesi sağlanmıştır. İyileştirilmiş görüntüler eşikleme 
işlemine tabi tutulduktan sonra çıktı görüntüleri üzerinde performans iyileştirilmesi yapılmıştır. Performans iyileştirme yönteminde damara ait olmayan damar benzeri görüntüler morfolojik işlemler kullanılarak yok edilmiştir. $\mathrm{Bu}$ aşama bağlı bileşen analizi kullanılarak önce küçük nesneler silinmiş daha sonrada damardan kopuk küçük boşluklar doldurulmuştur. Şekil 6'da eşikleme algoritmalarının performans iyileştirme sonuçları görsel olarak sunulmuştur. Şekil 6'da ilk sütunda orijinal görüntüler, ikinci sütunda Bulanık Mantık Tabanlı Eşikleme yöntem sonuçları, üçüncü sütunda Maksimum Entropi Tabanlı Eşikleme yöntem sonuçları, son sütunda Çoklu Eşikleme yöntem sonuçları gösterilmiştir.
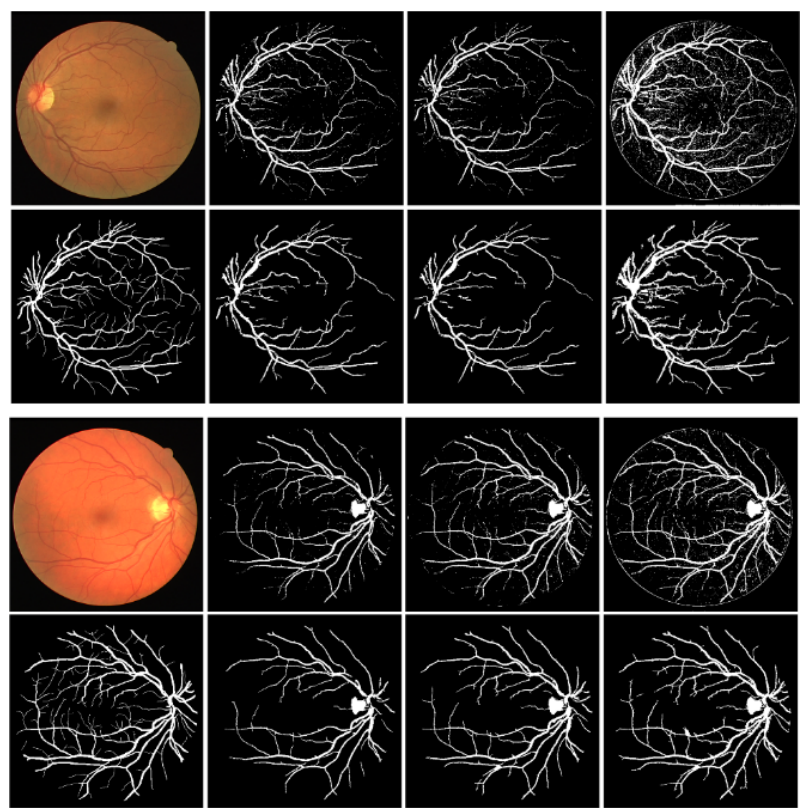

Şekil 6. Performans İyileştirme Sonuçları. Birinci satırlar eşikleme sonuçlarını, ikinci satırlar iyileştirme sonuçlarını göstermektedir. Orijinal görüntünün altındaki görüntüler 1.manuel bölütlenmiş gerçek zemin görüntüleridir.

Uygulanan yöntemin başarı ölçütünü hesaplamak için Doğruluk Oranı ölçüsü kullanılmıştır. Denklem (12)'de Doğruluk Oranı ölçütünün matematiksel ifadesi verilmiştir.

$$
A C C=\frac{T P+T N}{T P+F P+T N+F N}
$$

Burada, TP parametresi doğru pozitif, $F P$ parametresi yanlış pozitif, $T N$ parametresi doğru negatif ve $F N$ parametresi yanlış negatif pikselleri temsil eder. $A C C$ parametresi doğruluk oranını temsil eder. Hem bölütlenmiş görüntüde hem de gerçek zemin görüntüsünde aynı piksele ait ve piksel değerleri "1" olan piksellerin toplamı $T P$ parametresinin değerini oluşturur. Hem bölütlenmiş görüntüde hem de gerçek zemin görüntüsünde aynı piksele ait ve piksel değerleri "0" olan piksellerin toplamı TN parametresinin değerini oluşturur. Hem bölütlenmiş görüntüde hem de gerçek zemin görüntüsünde aynı piksele ait ve piksel değerleri bölütlenmiş görüntü için “ 0 ”, gerçek zemin görüntüsü için "1" olan piksellerin toplamı $F N$ parametresinin değerini oluşturur. Hem bölütlenmiş görüntüde hem de gerçek zemin görüntüsünde aynı piksele ait ve piksel değerleri bölütlenmiş görüntü için “1”, gerçek zemin görüntüsü için " 0 " olan piksellerin toplamı FP parametresinin değerini oluşturur.

Tablo 1'de uygulanan yöntem de kullanılan üç eşikleme yönteminden elde edilen sonuçlar gösterilmiştir. Uygulanan yöntem, DRIVE veri seti üzerinde hem test hem eğitim veri kümesi üzerinde denenmiş olup toplamda 40 görüntü üzerinde çalıştırılmıştır.

Tablo 1. Eşikleme yöntemlerinin doğruluk oran sonuçları

\begin{tabular}{|c|c|c|c|}
\hline $\begin{array}{l}\text { Görüntü } \\
\text { ismi }\end{array}$ & $\begin{array}{c}\text { Bulanık Mantık } \\
\text { Tabanlı } \\
\text { Eşikleme }\end{array}$ & $\begin{array}{c}\text { Maksimum } \\
\text { Entropi Tabanlı } \\
\text { Eşikleme }\end{array}$ & $\begin{array}{l}\text { Çoklu Eşikleme } \\
\text { Yöntemi }\end{array}$ \\
\hline 01_test & 0.9610 & 0.95864 & 0.9550 \\
\hline 02_test & 0.9511 & 0.95653 & 0.9579 \\
\hline 03_test & 0.9522 & 0.93426 & 0.9301 \\
\hline 04_test & 0.9491 & 0.95705 & 0.9570 \\
\hline 05_test & 0.9526 & 0.94855 & 0.9450 \\
\hline 06_test & 0.9485 & 0.94221 & 0.9136 \\
\hline 07_test & 0.9505 & 0.94895 & 0.9444 \\
\hline 08_test & 0.9510 & 0.94043 & 0.9148 \\
\hline 09_test & 0.9530 & 0.94627 & 0.9345 \\
\hline 10_test & 0.9586 & 0.95376 & 0.9518 \\
\hline 11_test & 0.9494 & 0.94976 & 0.9479 \\
\hline 12_test & 0.9550 & 0.95244 & 0.9072 \\
\hline 13_test & 0.9500 & 0.94601 & 0.9460 \\
\hline 14_test & 0.9617 & 0.95821 & 0.9344 \\
\hline 15_test & 0.9636 & 0.96398 & 0.9493 \\
\hline 16_test & 0.9562 & 0.95520 & 0.9536 \\
\hline 17_test & 0.9574 & 0.95023 & 0.9290 \\
\hline 18_test & 0.9569 & 0.95723 & 0.9454 \\
\hline 19_test & 0.9713 & 0.96701 & 0.9561 \\
\hline 20_test & 0.9582 & 0.95505 & 0.9110 \\
\hline 21_training & 0.9582 & 0.95968 & 0.9630 \\
\hline 22_training & 0.9533 & 0.95464 & 0.9524 \\
\hline 23_training & 0.9173 & 0.95349 & 0.8338 \\
\hline 24_training & 0.9382 & 0.94285 & 0.9435 \\
\hline 25_training & 0.9459 & 0.92455 & 0.9161 \\
\hline 26_training & 0.9545 & 0.94524 & 0.8448 \\
\hline 27_training & 0.9479 & 0.95131 & 0.9504 \\
\hline 28_training & 0.9493 & 0.95311 & 0.9523 \\
\hline 29_training & 0.9589 & 0.95624 & 0.9478 \\
\hline 30_training & 0.9447 & 0.93437 & 0.5305 \\
\hline 31_training & 0.9464 & 0.94877 & 0.9505 \\
\hline 32_training & 0.9609 & 0.95895 & 0.9602 \\
\hline 33_training & 0.9588 & 0.95740 & 0.9563 \\
\hline 34_training & 0.9213 & 0.92242 & 0.8836 \\
\hline 35_training & 0.9574 & 0.95969 & 0.9567 \\
\hline 36_training & 0.9400 & 0.93858 & 0.9420 \\
\hline 37_training & 0.9542 & 0.95534 & 0.9527 \\
\hline 38_training & 0.9524 & 0.94959 & 0.9481 \\
\hline 39_training & 0.9507 & 0.94576 & 0.9114 \\
\hline
\end{tabular}


Tablo 1'de verilen sonuçların alandaki birkaç yaygın yöntemden daha iyi performans gösterdiği görülebilir. DRIVE veri setindeki 40 görüntüye ait üç eşikleme yönteminin eşik değeri Tablo 2'de gösterilmiştir. Yapılan çalışmanın diğer geleneksel yöntemlerle karşılaştırılması Tablo 3'de verilmiștir.

Tablo 2. Eşikleme yöntemlerinin değerleri

\begin{tabular}{|c|c|c|c|}
\hline $\begin{array}{c}\text { Görüntü } \\
\text { ismi }\end{array}$ & $\begin{array}{c}\text { Bulanık Mantık } \\
\text { Tabanlı } \\
\text { Eşikleme }\end{array}$ & $\begin{array}{c}\text { Maksimum } \\
\text { Entropi Tabanlı } \\
\text { Eşikleme }\end{array}$ & $\begin{array}{c}\text { Çoklu } \\
\text { Eşikleme } \\
\text { Yöntemi }\end{array}$ \\
\hline 01_test & 78 & 84 & 81 \\
\hline 02_test & 96 & 81 & 96 \\
\hline 03_test & 61 & 90 & 64 \\
\hline 04_test & 103 & 74 & 102 \\
\hline 05_test & 66 & 80 & 72 \\
\hline 06_test & 60 & 84 & 64 \\
\hline 07_test & 78 & 84 & 84 \\
\hline 08_test & 56 & 83 & 64 \\
\hline 09_test & 60 & 85 & 65 \\
\hline 10_test & 69 & 85 & 75 \\
\hline 11_test & 101 & 79 & 101 \\
\hline 12_test & 61 & 86 & 67 \\
\hline 13_test & 76 & 85 & 80 \\
\hline 14_test & 69 & 87 & 73 \\
\hline 15_test & 81 & 86 & 87 \\
\hline 16_test & 83 & 84 & 87 \\
\hline 17_test & 65 & 87 & 68 \\
\hline 18_test & 74 & 84 & 79 \\
\hline 19_test & 71 & 83 & 75 \\
\hline 20_test & 57 & 88 & 62 \\
\hline 21_training & 90 & 84 & 93 \\
\hline 22_training & 86 & 80 & 88 \\
\hline 23_training & 67 & 104 & 71 \\
\hline 24_training & 92 & 82 & 93 \\
\hline 25_training & 48 & 91 & 62 \\
\hline 26_training & 52 & 88 & 59 \\
\hline 27_training & 91 & 81 & 94 \\
\hline 28_training & 94 & 81 & 95 \\
\hline 29_training & 68 & 79 & 75 \\
\hline 30_training & 39 & 98 & 44 \\
\hline 31_training & 114 & 71 & 112 \\
\hline 32_training & 75 & 80 & 80 \\
\hline 33_training & 82 & 85 & 86 \\
\hline 34_training & 85 & 86 & 88 \\
\hline 35_training & 92 & 82 & 94 \\
\hline 36_training & 84 & 86 & 87 \\
\hline 37_training & 96 & 80 & 98 \\
\hline 38_training & 74 & 83 & 79 \\
\hline 39_training & 61 & 91 & 64 \\
\hline 40_training & 63 & 79 & 67 \\
\hline
\end{tabular}

Tablo 3. Diğer yöntemlerle performans karşılaştırması

\begin{tabular}{lc}
\hline Literatürdeki Yöntemler & Doğruluk Oranı \\
\hline BenjunYin vd. [22] & 0.943 \\
B.Barkana vd. [23] & 0.950 \\
Peter Bankhead vd. [24] & 0.937 \\
M.M. Fraza vd. [11] & 0.947 \\
J.Zhang vd. [17] & 0.943 \\
Önerilen Yöntem & \\
\hline Bulanık Mantık Tabanlı Doğruluk Oranı & 0.952 \\
Maksimum Entropi Tabanlı Doğruluk & 0.950 \\
Oranı & \\
Eşikleme Tabanlı Doğruluk Oranı & 0.925 \\
\hline
\end{tabular}

\section{Sonuçlar}

$\mathrm{Bu}$ makalede, paylaşıma açık olarak sunulan DRIVE veri seti üzerinde morfolojik işlemlere dayalı bir damar iyileştirme yöntemi kullanılmıştır. Damar iyileştirme aşamasından sonra Çoklu Eşikleme, Bulanık Mantık Tabanlı Eşikleme ve Maksimum Eşikleme yöntemleri kullanılarak damar bölütlemesi yapılmışırı. $\mathrm{Bu}$ yöntem temelde morfolojik işlemlere dayanmış olsa da asıl amaç eşikleme algoritmalarının yöntem üzerindeki performanslarının karşılaştırılmasıdır. Eşikleme yöntemleri, doğası ne olursa olsun tüm veriler üzerinde kullanılabilir. Ancak, farklı eşikleme yöntemlerinin aynı iyileştirilmiş görüntü üzerinde farklı sonuçlar verdiği gözlemlenmiş̧ir. Bu makalede, Bulanık Mantık Tabanlı Eşikleme yönteminin ortalama doğruluk oranı 0.952 olarak hesaplanmış ve diğer iki eşikleme yönteminden daha yüksek bir değere sahip olmuştur.

Bu makalede elde edilen deneysel sonuçlar tatmin edici bir seviyededir. Önerilen yöntem geliştirilmeye açıtır. Halka açık bir veri seti kullanıldığı için karşılaştırması ve doğruluğu test edilebilir durumdadır. İleriki çalışmalarımızda, bu makalede elde ettiğimiz eşikleme yöntemleri tecrübelerimizi kullanarak popüler algoritmalar ile görüntü eşikleme üzerinde çalışmayı hedeflemekteyiz.

\section{Teşekkür}

$\mathrm{Bu}$ çalışma, İnönü Üniversitesi bilimsel araştırma ve koordinasyon birimi tarafindan FDK-2020-2109 proje numarası ile finanse edilmiştir.

\section{Çıkar çatışması}

Yazarlar çıkar çatışması olmadığını beyan etmektedir.

Benzerlik oranı (iThenticate): $\% 12$

\section{Kaynaklar}

[1] J. Staal, M. D. Abràmoff, M. Niemeijer, M. A. Viergever, and B. Van Ginneken, "Ridge-based vessel segmentation in color images of the retina," IEEE Trans. Med. Imaging, vol. 23, no. 4, pp. 501-509, 2004, doi: 10.1109/TMI.2004.825627.

[2] J. V. B. Soares, J. J. G. Leandro, R. M. Cesar, H. F. Jelinek, and M. J. Cree, "Retinal vessel segmentation using the 2-D Gabor wavelet and supervised classification," IEEE Trans. Med. Imaging, vol. 25, no. 9, pp. 1214-1222, Sep. 2006, doi:10.1109/ TMI.2006.879967.

[3] U. T. V. Nguyen, A. Bhuiyan, L. A. F. Park, and K. Ramamohanarao, "An effective retinal blood vessel segmentation method using multi-scale line detection," Pattern Recognit., vol. 46, no. 3, pp. 703-715, 2013, doi: 10.1016/j.patcog.2012.08.009.

[4] C. A. Lupaşcu, D. Tegolo, and E. Trucco, "FABC: Retinal vessel segmentation using AdaBoost," IEEE Trans. Inf. Technol. Biomed., vol. 14, no. 5, pp. 12671274, 2010, doi: 10.1109/TITB.2010.2052282.

[5] M. Niemeijer, J. Staal, B. Van Ginneken, M. Loog, and M. . Abramoff, "Comparative study of retinal vessel segmentation methods," in 2015 IEEE International Conference on Computational Intelligence and 
Computing Research, ICCIC 2015, 2004, pp. 9-18.

[6] D. Marín, A. Aquino, M. E. Gegúndez-Arias, and J. M. Bravo, "A new supervised method for blood vessel segmentation in retinal images by using gray-level and moment invariants-based features," IEEE Trans. Med. Imaging, vol. 30, no. 1, pp. 146-158, 2011, doi: 10.1109/TMI.2010.2064333.

[7] M. M. Fraz et al., "Blood vessel segmentation methodologies in retinal images - A survey," Comput. Methods Programs Biomed., vol. 108, no. 1, pp. 407433, 2012, doi: 10.1016/j.cmpb.2012.03.009.

[8] E. Ricci and R. Perfetti, "Retinal blood vessel segmentation using line operators and support vector classification," IEEE Trans. Med. Imaging, vol. 26, no. 10, pp. 1357-1365, 2007, doi:10.1109/TMI.2007. 898551.

[9] B. Toptaş and D. Hanbay, "Retinal blood vessel segmentation using pixel-based feature vector," Biomed. Signal Process. Control, vol. 70, 2021, doi: https://doi.org/10.1016/j.bspc.2021.103053.

[10] A. M. Mendonça and A. Campilho, "Segmentation of retinal blood vessels by combining the detection of centerlines and morphological reconstruction," IEEE Trans. Med. Imaging, vol. 25, no. 9, pp. 1200-1213, 2006, doi: 10.1109/TMI.2006.879955.

[11] M. M. Fraz et al., "An approach to localize the retinal blood vessels using bit planes and centerline detection," Comput. Methods Programs Biomed., vol. 108, no. 2, pp. 600-616, 2012, doi: 10.1016/j.cmpb.2011.08.009.

[12] M. D. Saleh and C. Eswaran, "An efficient algorithm for retinal blood vessel segmentation using h-maxima transform and multilevel thresholding," Comput. Methods Biomech. Biomed. Engin., vol. 15, no. 5, pp. 517-525, 2012, doi: 10.1080/10255842.2010.545949.

[13] B. Zhang, L. Zhang, L. Zhang, and F. Karray, "Retinal vessel extraction by matched filter with first-order derivative of Gaussian," Comput. Biol. Med., vol. 40, no. 4, pp. 438-445, 2010, doi:10.1016/ j.compbiomed.2010.02.008.

[14] M. E. Martinez-Perez, A. D. Hughes, S. A. Thom, A. A. Bharath, and K. H. Parker, "Segmentation of blood vessels from red-free and fluorescein retinal images," Med. Image Anal., vol. 11, no. 1, pp. 47-61, 2007, doi: 10.1016/j.media.2006.11.004.

[15] S. Holm, G. Russell, V. Nourrit, and N. McLoughlin, "DR HAGIS - a fundus image database for the automatic extraction of retinal surface vessels from diabetic patients," J. Med. Imaging, vol. 4, no. 1, p. 014503, 2017, doi: 10.1117/1.jmi.4.1.014503.

[16] C. Zhu et al., "Retinal vessel segmentation in colour fundus images using Extreme Learning Machine," Comput. Med. Imaging Graph., vol. 55, pp. 68-77, 2017, doi: 10.1016/j.compmedimag.2016.05.004.

[17] J. Zhao et al., "Automatic retinal vessel segmentation using multi-scale superpixel chain tracking," Digit. Signal Process. A Rev. J., vol. 81, pp. 26-42, 2018, doi: 10.1016/j.dsp.2018.06.006.

[18] S. Kotte, P. Rajesh Kumar, and S. K. Injeti, "An efficient approach for optimal multilevel thresholding selection for gray scale images based on improved differential search algorithm," Ain Shams Eng. J., vol. 9, no. 4, pp. 1043-1067, 2018, doi:10.1016/ j.asej.2016.06.007.

[19] H. Üzen and A. Karci, "Kumaş Hatası Tespiti i çin Entropi i le Geliştirilmiş Otomatik Eşikleme Yöntemi Automatic Thresholding Method Developed With Entropy For Fabric Defect Detection," pp. 14-17.

[20] P. K. Sahoo, S. Soltani, and A. K. C. Wong, "A survey of thresholding techniques," Comput. Vision, Graph. Image Process., vol. 41, no. 2, pp. 233-260, 1988, doi: 10.1016/0734-189X(88)90022-9.

[21] K. Rajesh Babu, V. A. S. Chakravarthy, S. Sandeep Reddy, G. Phani Kumar, and M. Vamsi Kumar, "Automated brain tumour detection in MRI images using threshold based FCM," Int. J. Sci. Technol. Res., vol. 8, no. 12, pp. 224-227, 2019.

[22] B. Yin et al., "Vessel extraction from non-fluorescein fundus images using orientation-aware detector," Med. Image Anal., vol. 26, no. 1, pp. 232-242, 2015, doi: 10.1016/j.media.2015.09.002.

[23] B. D. Barkana, I. Saricicek, and B. Yildirim, "Performance analysis of descriptive statistical features in retinal vessel segmentation via fuzzy logic, ANN, SVM, and classifier fusion," Knowledge-Based Syst., vol. 118, pp. 165-176, 2017, doi:10.1016/j.knosys. 2016.11.022.

[24] P. Bankhead, C. N. Scholfield, J. G. McGeown, and T. M. Curtis, "Fast retinal vessel detection and measurement using wavelets and edge location refinement," PLoS One, vol. 7, no. 3, 2012, doi: 10.1371/journal.pone.0032435. 